\title{
Historic Landscape Characterisation. An Experimental Case Study
}

\author{
By Domenico Chizzoniti* \\ Letizia Cattani \\ Monica Moscatelli ${ }^{+}$ \\ Luca Preis ${ }^{\dagger}$
}

Gardens and historic parks represent an important cultural heritage resource in the urban structure. This paper analyses a case study in order to encourage the active "conservation" of open spaces. The physical setting of this research is an area in Milan included between the Guastalla Garden and the nearby Garden of the Sormani State Library. Our hypothesis explores different solutions in order to find new physical connections between these two historical gardens, through the design of temporary and reversible architectural structures dedicated to public functions such as exhibition, cultural enterprises and social facilities. The aim of this strategy is to enhance historical sites, not just to protect them from damaging development. The presence of public functions leads us to define a new approach to the concept of enhancement, and allows us to translate reversible structures into an item able to transform the site and develop the quality of life in the city.

Keywords: Enhancement, Landscape, Reversible, Temporary, Urban park.

\section{Introduction}

This study arises from a survey for the city of Milan, focusing on the relationship between built and open spaces. In particular, we focused on the importance of free spaces, like urban parks and gardens, which constitute the system of open spaces. These, such as historical and modern squares, have always had a peculiar role in the construction of the city, due to their ability to balance the urban structure, as well as their contribution in defining the identity and the urban character that constitute the city's image.

All open spaces included in the built fabric of the contemporary city, showing continuity, are extremely important in order to emphasize the enormous inherent potential of the urban structure, and improve the quality of life in the city. In spite of the existence of these potentialities in the city, the open space is still frequently called "green" and plays a secondary role in the

\footnotetext{
* Assistant Professor, Polytechnic University of Milan, Italy.

* Adjunct Professor, Polytechnic University of Milan, Italy.

${ }^{+}$PhD Candidate and Research Assistant, Polytechnic University of Milan, Italy.

${ }^{\dagger}$ Adjunct Professor, Polytechnic University of Milan, Italy.
} 
construction of the urban landscape (Maas et al. 2006). Additionally, the open green space could be helpful in supporting the urban experience, the social interaction and the development of the sense of community through all the facilities, which can be established there.

With regard to these spaces, several questions concerning their quality have been raised by the recent literature, namely their lack of integration in a recognized urban typology and all the consequences that this might bring (Meijeringa et al. 2015).

Urban park studies often inspect specific sites separately from other factors, or try to underline only a particular aspect or benefit, like the recreational or ecological value (Ibes 2015, Saurí et al. 2009, Cranz et al. 2004, Lindsey 2003).

Despite the foregoing, in terms of city structure and cohesion, the attitude of indifference shown towards the qualitative definition of these spaces, gardens or parks tends to reduce them to nothing more than another index in the city's statistics (Harnik 2010).

Therefore, it is necessary to have a new attitude in reading the urban condition of free spaces, underlining the importance of the quality of landscape (Gold 1972). We usually consider fundamental to preserve these spaces through a policy, by implementing prescriptions and rules as guidelines to protect them. Now and then, the policy of preservation should be linked to the idea that an adequate use of these spaces might induce a vital condition to protect them. In other words we wonder how many structures, gardens, public spaces, and obviously architectures should be conserved without any functional intervention in order to preserve them "as a museum of themselves" (Kaźmierczak 2013). This idea has started by implementing a positive use of these spaces, as a vital condition to their defense, recognizing comprehension and enjoyment as the true potential to the development and experience of the city (Waldheim 2006).

\section{New Approaches to Open Spaces}

In complex cities like Milan, it is of paramount importance to be fully aware of the historical landscape, to which the concepts and practices of production, leisure and protection have always been closely linked.

However, this dimension of the urban landscape has been lost as a result of the modern movement, where the sectorial zoning does not allow for the coexistence of several roles, and the concept of green space appears vaguely, stretching throughout the entire city homogeneously, amorphously and residually.Therefore, the original concept of landscape needs to be urgently restored.

Several authors (Ibes 2015, Saurí et al. 2009, Cranz et al. 2004, Lindsey 2003), searching for new strategies for developing a multifunctional landscape and its understanding, stated that a continuous and structuring fabric should be implanted in the open spaces of the city. Within these spaces, the systemic 
vision of the landscape would appear as a fundamental structure of this continuum, according to a practice of long course in the philosophy of landscape architecture.

It is clear that the contradiction between the formal extension of the protections and the effects of pressure settlement finds its "raison d'être" in a system of constraints and requirements that should rediscover its effectiveness and redefine its operational tools.

Indeed, there is a deep disconnection between the good intentions of the institutions involved and their impact on the activities of government land, where the landscape quality, designed both in terms of aesthetics and historical identity, are almost always seen as an obstacle to development rather than as an opportunity. In the search for the lost concept of landscape, references are frequently made to the aesthetic, social, ecological, economic and cultural components, and consequently to the role of protection, production and leisure.

Over the last ten years, the central government, the region and the local authorities, thanks to the implementation of the European Landscape Convention (COE 2000) and the activity carried out by universities and environmental groups have put a lot of energy and resources into the preparation of research on landscape heritage.

However, the widespread feeling among traders is that the results of these studies are confined in a specialized field and end up remaining unheard or sacrificed to the interests considered strategically or economically relevant.

\section{The Role of Historical Landscape}

From our point of view and experience, we believe that any attempts at overcoming the contradiction, seemingly irreconcilable, between urbanization and environmental protection, is an interesting challenge in line with the idea of "building new landscape values coherent and integrated" pursued by the Code and the European Landscape Convention (COE 2000).

As mentioned above, nowadays the term "landscape" takes a wide range of meanings, not only aesthetic-artistic ones, but also of sociological, anthropological and historical nature. For these reasons, trying to promote a new concept of landscape seems to be more timely than ever, arriving to the creation of "a development model capable of producing new relationships, new environmental quality, new vitality to towns and small cities" (ICOMOS 2014).

In our study, leisure is an essential component of the landscape in the idea of reading green places in the urban area, because it structures, characterizes, and provides continuity to the urban fabric through its free spaces, open spaces and suburbs, to the countryside and promoting an articulated relationship between this old dichotomy city-countryside.

Taking cue from the daily working activities in the area, and considering them recognized by public and private operators, we have highlighted some 
prospects for promoting the quality of landscape, by focusing our research on different aspects:

\section{Infrastructure as Devices Landscaping Design}

The Lombardy region and the city of Milan have always been characterized by several projects of territorial scale, also included urban parks and gardens as a category. From the example of Leonardo da Vinci, with his work on the regimentation of the navigation system of canals (Cali and Capurro 2015), up to Carlo Cattaneo and his idea of Lombardy as a polycentric city (Cattaneo 1972).

This point of view would allow the interpretation of the new projects for the realization of new medium-large size infrastructures as an opportunity for landscaping design, also implemented through the creation of artifacts of great architectural quality, and as the possibility of enriching the territorial stratification.

\section{The Restoration of the Landscape}

In recent years, the economic crisis has led to the dismissal of many productive activities and crafts, beyond the boundaries of the areas' industrial history. Their redevelopment could be understood not really as a form of replacement housing, but rather as an opportunity to experience a project of "landscape restoration", which should be based on new skills and appropriate resources.

\section{The Protection of Abandoned Industrial Landscapes}

The disposal of the great centers of Lombard industrial production provides an opportunity to rethink - in terms of cultural heritage - of vast areas that have so far been considered, in project and program planning, only as areas of expansion, united by interventions based on the principle of "tabula rasa". Due to the size and nature of these settlements, the scale of analysis, enhancement and protection can only be applied to the landscape.

\section{The Landscape Function of Agriculture}

The land consumption by urban areas is affecting more and more agricultural land, whose extension in the Lombardy region has been reduced by almost 27,000 hectares in recent years. At the same time, the intensive land exploitation threatens to abandon some traditional crops that have a clear meaning in the landscape.

It is interesting to investigate how landscape preservation and protection of the productive activity, in this case, converge towards a common goal. It is also well-known that the strategies for the conservation of productive activities can generate profitable benefits to the protection of landscape. 
New Frontiers: The City Landscape of the Twentieth Century and the Scenic Value of the Archaeological Areas

The great transformation of the landscape of Lombardy during the twentieth century also produced urban fragments of considerable interest. This is a new frontier of landscape protection, facilitated by the explicit recognition that occurred in the last revision of the Code, namely the drafting of decisions relating to urban centers extended with strong identity characteristics (Bianconi 1787). Alternatively, those related to archaeological sites, often neglected in the assessments of natural landscape, but fundamental in relation to the region, in terms of design, modeling and qualification of the territory (Marinoni 2001).

Our project proposal aims to identify a new approach to the design of open spaces that includes the creation of a multifunctional structure of landscape, dedicated to production and leisure in an urban context. For this purpose, the green spaces included in this study can and should be an expression of the current landscape continuum, allowing the occurrence of both historical processes and of the fundamental physiological cycles contributing to the harmonious and well-balanced development of the city. With the purpose of better understanding the quality of landscape, and based on the idea that those free spaces should appear as fundamental elements of the urban structure (Jacobs 1961), we tried to develop the idea that non-permanent structures and functions could represent a solution to improve the accessibility to new patterns of use.

\section{The Green System in Milan}

Through a closer approach to the system of open spaces of Milan, we worked on the existence of typologically qualified spaces, i.e. historical structures with defined characters. Then we found many other kinds of open spaces without any typological attribution, that used to be no less important than the former (Cottini 1994). Of course, urban parks play an important role in preserving and promoting the health of the citizens (Cranz and Boland 2004), who are often exposed to negative factors, such as noise, pollution, and so on.

Then the urban parks, such as Sempione Park and Porta Venezia Park. Sempione Park is a historical urban park in downtown Milan. Due to its proximity to the "Sforzesco" castle, the park is also a tourist attraction. The park area includes the Palace of Arts, the Civic Arena, the Milan Aquarium (Figure 1).

We can recognize three main categories: regional, peri-urban parks, and urban parks that affect the city of Milan. The Parco Nord Milano and Parco Agricolo Sud Milano belong to the first species (Ibes 2015, Cranz and Boland 2004). Then the Forlanini Park with Trenno Park (linked to the "Bosco in città" and "Parco delle cave") are two typical examples of peri-urban parks.

The Guastalla Garden is the oldest park in Milan with a rich history that began in 1555, when Paola Lodovica Torelli, Countess of Guastalla, acquired a 
plot of land in Milan to build a Christian school for girls from noble families (The Catholic Encyclopedia). This congregation of women was founded for the protection and reclamation of girls (Rosignoli 1686, Various Authors 1881).

Figure 1. The Green System in Milan

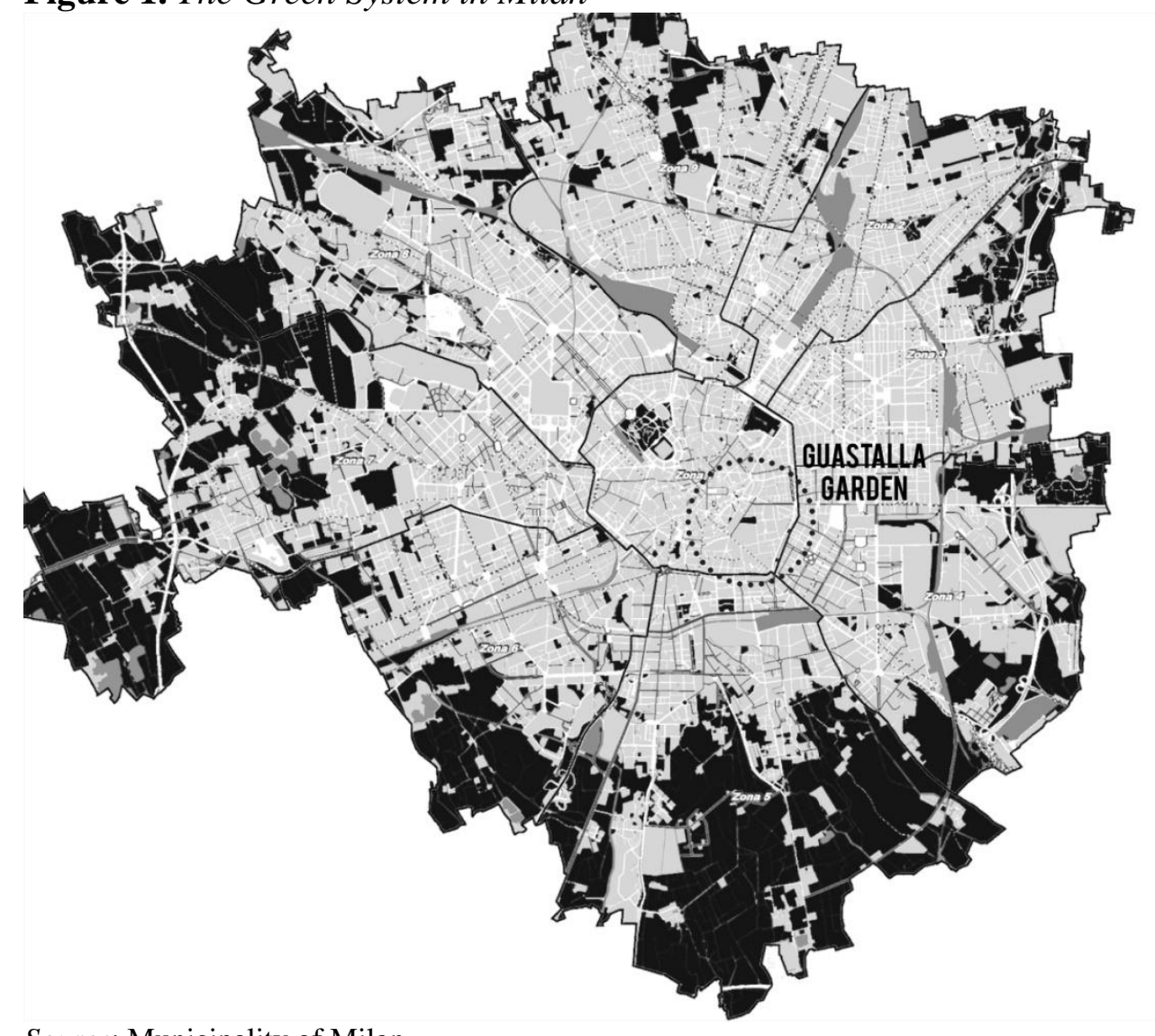

Source: Municipality of Milan.

The Institute of the Guastallines, also founded by the Countess Torelli, is still in existence (Cassi Ramelli 1971). Around the school, a magnificent Italian garden was created (Figure 2).

In 1938, the territory of Guastalla gardens along with the school building belonged to the community (Bagnoli 1971). When the school moved to the ancient city of Monza, near Milan, the gardens were combined with Guastalla (Cima 1925), located next to the garden of the Sormani Palace. In 1939, the garden became a public park and still is one of the most famous parks in the city (Morigia 1603). In the center of the park, there is a pond with goldfish in the Baroque style, decorated with white granite and surrounded by high terraces with connecting stairs, while a lot of rare and beautiful plants are grown there (De Carlo 1998). A neoclassical chapel and several statues are also located in the park. 
Figure 2. Map of the "Astronomi di Brera", 1804

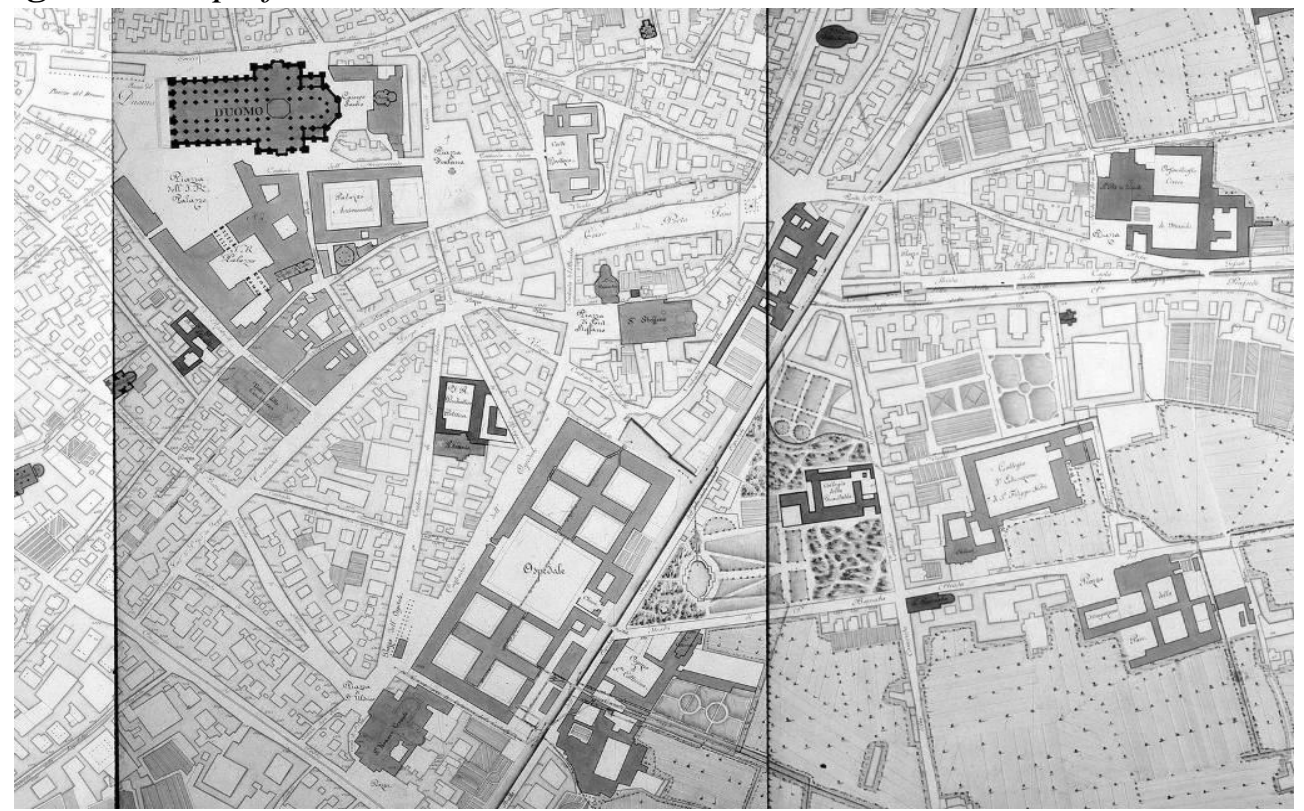

Source: University of Milan, Brera Astronomical Museum - Botanical Garden.

\section{A Case Study: The "Giardino Della Guastalla"}

With regard to the space morphology, the project approach starts from the reconstruction of the area near the College of Guastalla, expanding to the Garden of the Sormani State Library (Mezzanotte and Bascapè 1968). This hypothesis tried to physically join two historical gardens, which are currently sometimes discarded due to their still improper connection, despite their excellent site position, just in the middle of downtown Milan (Gerla 1956, Zagni 1987).

Therefore, the first intention was to connect the two structures, separated by Paolo Andreani street and a block of residences, which were quite insignificant from an architectural point of view, except one of them which was extremely interesting: the building created by Ghidini and Mozzoni.

We explored many solutions with different strategies as a project-study:

Figure 3. Masterplan

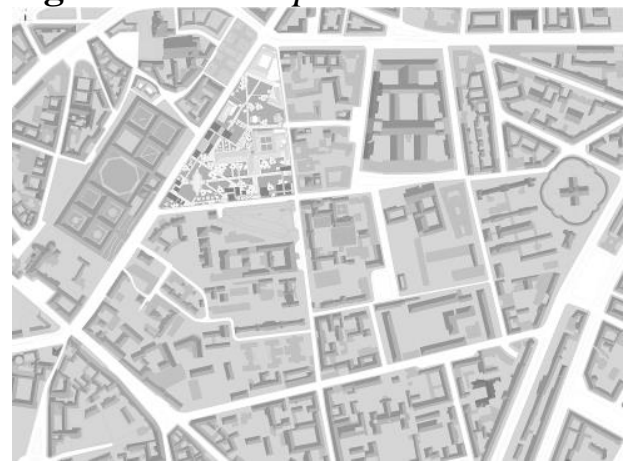

Figure 4. General Plan

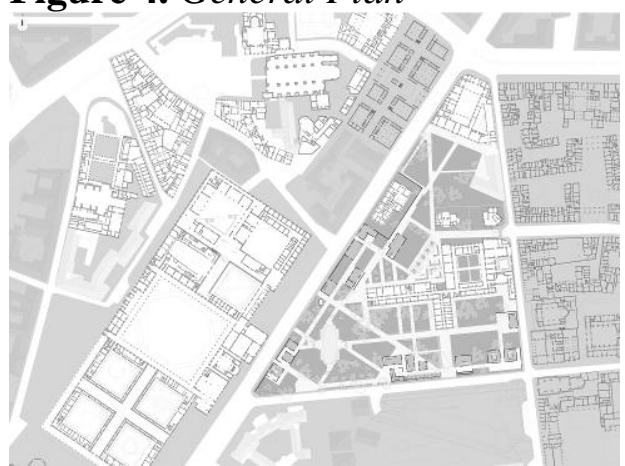

Source: (project by ADL Laboratory. D.Chizzoniti) E. Carraro, F. Pisetta. 
1. The preliminary study (this project was done with Elisa Carraro and Federica Pisetta). This project aims to be light: in fact, it includes the realization of a united structure for temporary use that can be easily integrated - and hidden - into the parks (Figure 3 and Figure 4).

That is why the building is still less than $10 \mathrm{~m}$ of height. Moreover, the aim is extended to safeguard and protect the original structure of the area with its trees, drifting and moving the foreseen pathways and structure. The project is based on a module of $1.75 \mathrm{~m}$ and its double of $3.50 \mathrm{~m}$. It is mainly based on three elements: the cage - or grid - that gives shape to open-air passages, pavilions and pathways.

The cage is the basic part in the project, because it creates continuity and defines the area. It is initially developed parallel to Francesco Sforza street in the Palazzo Sormani's garden with the little module, then it expands between and inside the pavilions.

The second part, instead, is developed parallel to St. Barnaba street until the corner with Guastalla street with the 3.75 m module. The cage has different functions: sometimes it "digs" pavilions' volumes, sometimes it links and crosses them, also with elevated pathways.

The differentiation between the two modules is based on their function and use: for great flows of people the major one is used, and vice versa, in order to allow the permeability with the surroundings. The material used for the structure is tube-shaped steel.

Sixteen pavilions are arranged and organized along the whole cage development (Figure 5 and Figure 6).

\section{Figure 5. Ground Floor}

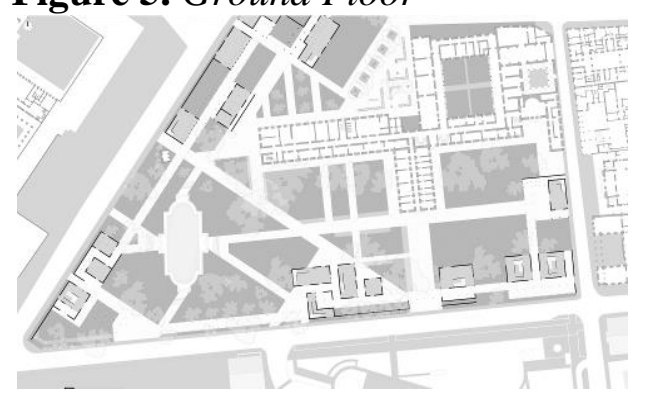

Figure 6. First Floor

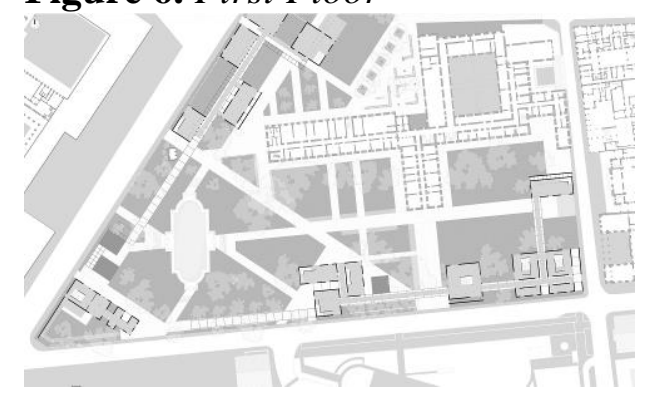

Source: (project by ADL Laboratory. D.Chizzoniti) E. Carraro, F. Pisetta.

These are rectangular or square blocks with different building areas, in order to host different functions (Figure 7 and Figure 8). 
Figure 7. Cross Sections

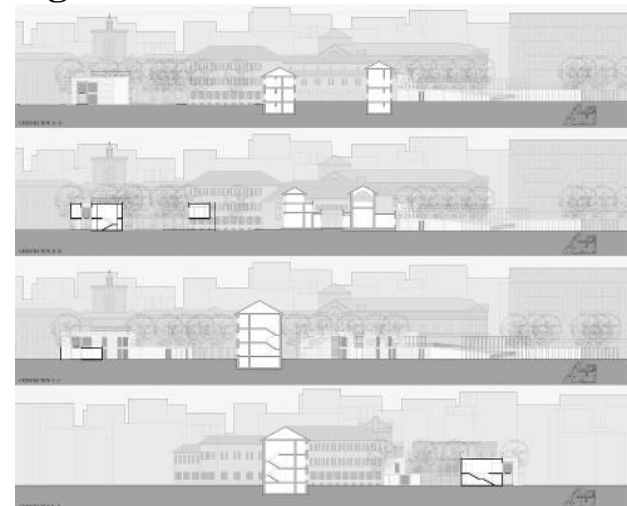

Figure 8. Longitudinal Sections

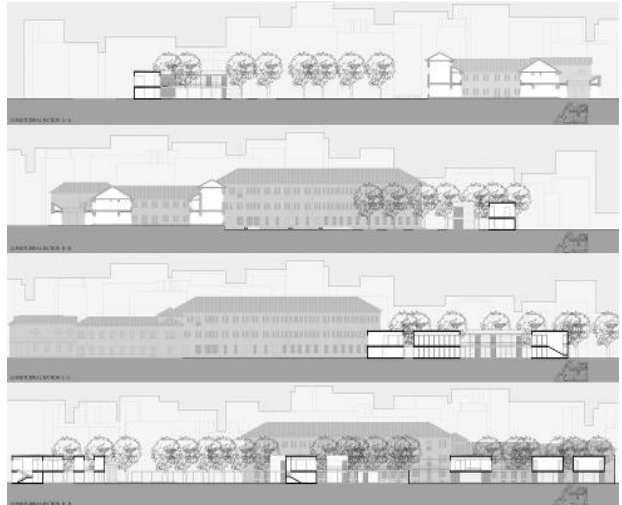

Source: (project by ADL Laboratory. D.Chizzoniti) E. Carraro, F. Pisetta.

Externally, they are covered with wooden planks to create a visual continuity in the gardens. All structures have flat roofs and facades where opaque and glass surfaces compose the wall, according to the modules. The inner space of the pavilions remains open and because of that, it was chosen to use pillars instead of bearing walls. Inner subdivision between spaces is given through shifting panels that can be arranged differently for each situation. No differentiation exists between the functions that the pavilions have to host: the project was made in order to be flexible and adaptable for each situation. Surely, they can be used for expositions and for leisure, or for the improvement and extension of the spaces of the nearby library and university.

The project is intended to maintain the characteristics of the nearby urban structure, developing pathways that run parallel to Francesco Sforza street, St. Barnaba street and Guastalla street. For the ground connections between pavilions, wooden runways are used.

They are a little bit elevated from the ground in order to keep the actual state of the park intact. In order to allow the whole unification of the two parks, it was chosen to close Paolo Andreani street to motor vehicles and to integrate it in the project as a ground passage (Figure 9 and Figure 10).

Figure 9. Axonometric view

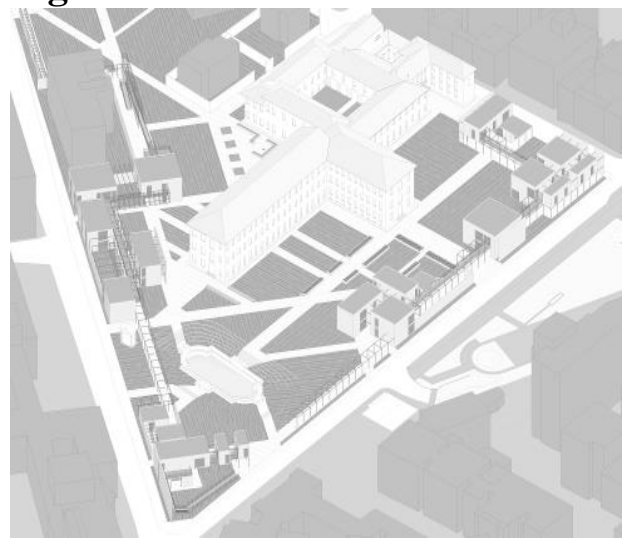

Figure 10. Physical model

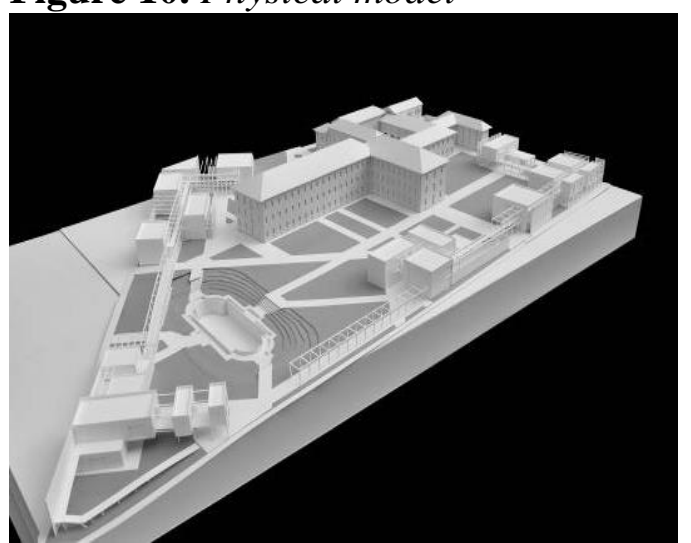

Source: (project by ADL Laboratory D.Chizzoniti) E. Carraro, F. Pisetta.. 
The structure of the park is really complex because of the passages that divide the gardens in numerous green areas. Although the gardens are united in the project, they are still completely different. That is also the aim: partly maintaining the differentiation.

The project should revitalize the area, exalting an important historic heritage for Milan, such as the boarding school Guastalla and its park.

Figure 11. Masterplan

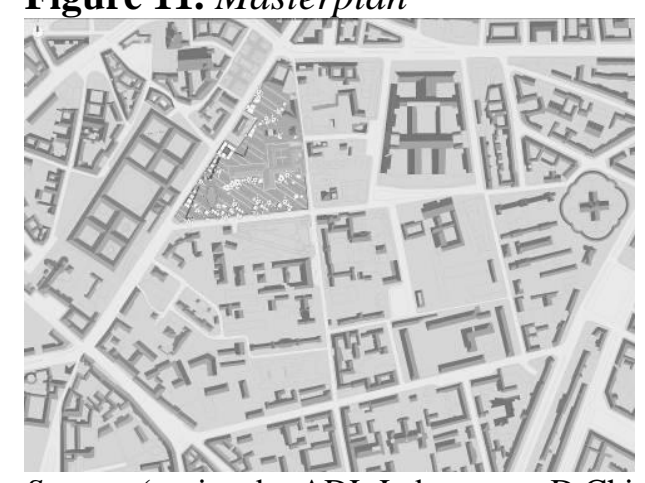

Figure 12. Roof Plan

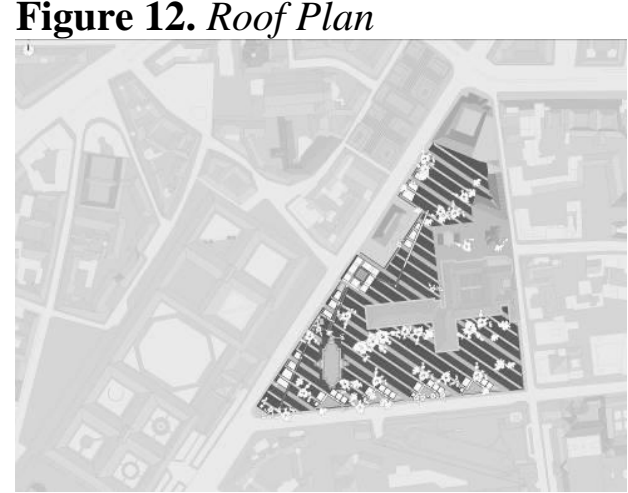

Source: (project by ADL Laboratory. D.Chizzoniti) T. Li, F. Olivieri.

2. The definitive study (this project was done with Francesca Olivieri and Tan Li). This stage mainly aims to give back to the city of Milan two historically important parks, i.e. the one of the Sormani Library and the one of the College of Guastalla, which are currently experiencing a situation of both proximity and separation. Therefore, the main objective is to unite them both functionally and compositionally through the design of structures for temporary use and dedicated to the public (Figure 11 and Figure 12).

The project consists of a central main body, thought to be the only nontemporary space, which gives origin to elevated routes defined by a modular grid. These paths are running in the directions of the two gardens, and along them exhibition spaces are placed in series, on different levels. On the southern side, other pavilions are developed modularly along the boundary wall of the park. A necessary condition for the unification of the two areas is the closure of San Barnaba street, which is maintained only in the portion providing access to the private residences in the eastern part (Figure 13 and Figure 14).

Figure 13. Ground Floor

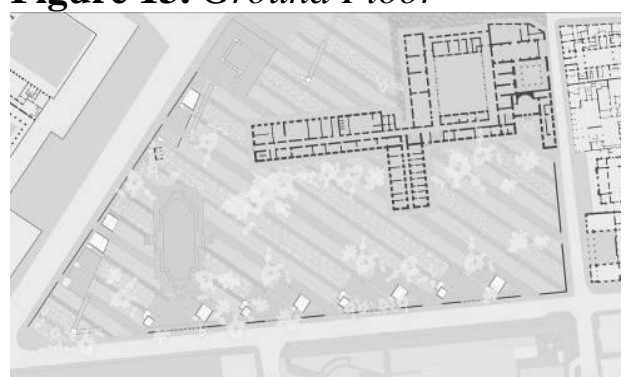

Figure 14. First Floor

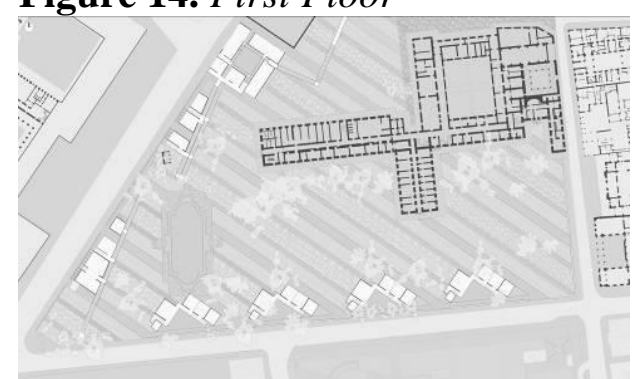

Source: (project by ADL Laboratory. D.Chizzoniti) T. Li, F. Olivieri. 
The architectural system is held together through the use of uniform directions and the definition of a steady pace. There are three directions, deriving from the Palazzo Sormani, from the Guastalla and the $\mathrm{Ca}^{\prime}$ Granda building with its axis, Sforza street; these give rise to the axes of elevated routes, the entrances on the south side and the pavilions located along the main road, respectively. The latter have a constant size at a pace we call C-B-A-B-C.

Therefore, it implies the creation of a module, whose width dimensions are: 6 meters for the first pavilion, 2 meters for the passage which connects to the main ramp, 8 meters for the second pavilion, other 2 meters of passage and then 6 meters for the third pavilion. Each module is separated from the next one by a passage of 4 meters, which provides access to the park from the road. In order to further strengthen this compositional scheme, it was decided to treat the green parts in the same way; lawns alternate, separated by graveled walkways, while the main passages are defined by wooden walkways. Despite their fixed width, pavilions widely vary by size, because the length is defined by the direction of the ramp (Figure 15 and Figure 16).

A further articulation takes place in height. In order to connect the pavilions to the main walkway, the floor heights are always different but sufficient to allow the habitability below them and access to the roof. The concept of the variation of the floor levels in accordance with the progress of the ramp is maintained even in the articulation of the central building. The route, which "enters" from the garden side of Guastalla at the second and third floors and "exits" towards the Sormani on the first floor, is built around a courtyard, along which there are the entrances to the various areas, thought to be used such as classrooms.

This building is the effective union between the two gardens both for its distributional value and its location. In fact, it is placed at the center of the Sforza street front and represents, with its free ground floor, an intention of permeability towards the urban context.

Despite the strong unifying intent, it is important to stress the need to maintain a certain degree of identity of the two spaces; for this reason, regarding the Sormani area, a different function has been thought, more intimate than the exhibition, which is to establish reading rooms, no longer raised but at a ground level.

Figure 15. Cross Sections

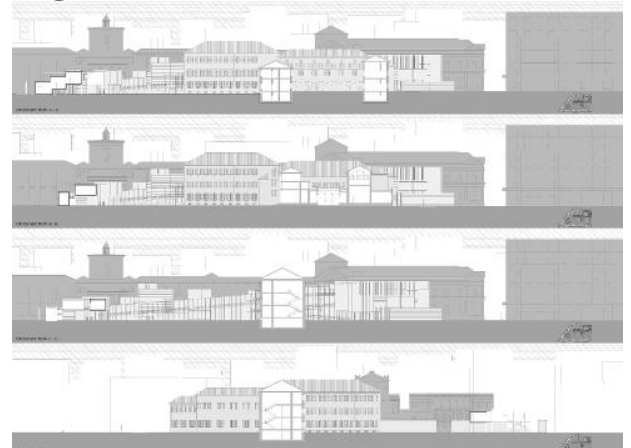

Figure 16. Longitudinal Sections

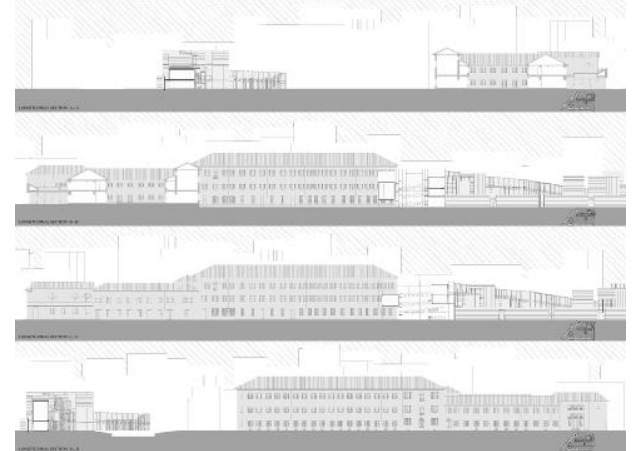

Source: (project by ADL Laboratory. D.Chizzoniti) T. Li, F. Olivieri. 
The same pace defined above determines the nuclei of the southern side which are designed to give rise to a small courtyard without obstructing the visibility toward the Guastalla building. The function here is more commercial; it can predict the presence of small areas of food or services.

With regard to the technological choices, the orientation is toward the structural wood for the halls, and steel structures for the grid containing the ramps. The surfaces, in which there are full-length windows, are covered in wood to create continuity with the surrounding natural environment (Figure 17 and Figure 18).

Figure 17. Axonometric View

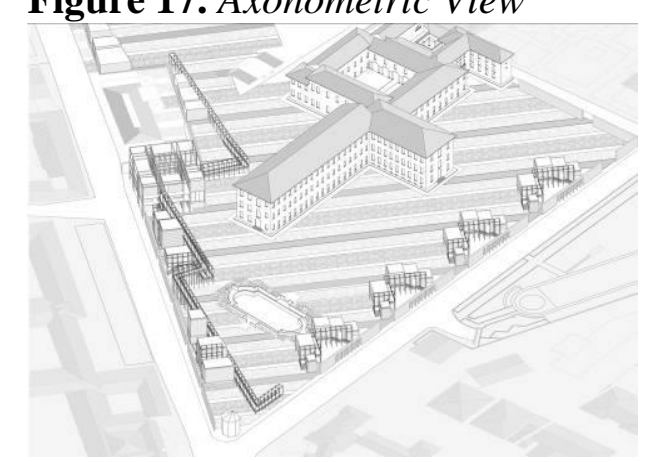

Source: (project by ADL Laboratory. D.Chizzoniti) T. Li, F. Olivieri.
Figure 18. Physical Model

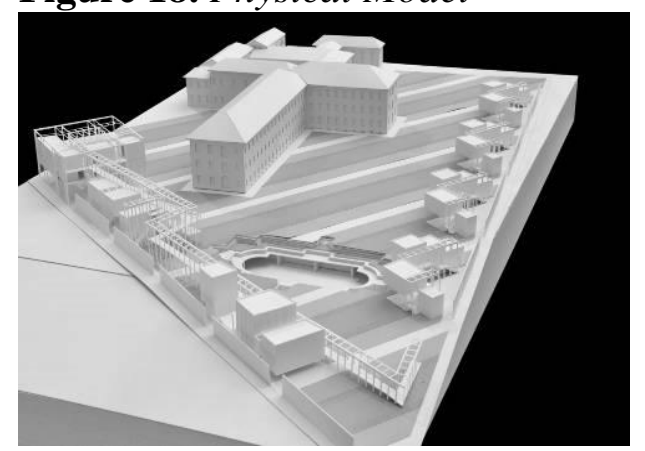

\section{Conclusions}

Our research group tries to make some experiments in order to explore different solutions to find new connections between the potentialities of the two gardens and the historical buildings surrounding them. Therefore, the main objective is to unite them both functionally and compositionally through the design of structures for temporary use and dedicated to the public.

As a result of our exploration work and survey of existing facilities and the park system connected, it was appropriate to provide "guidelines", i.e. operational criteria, to public authorities, bodies and associations operating in these areas, aimed at developing the methods of conservation/enhancement of plant areas and their context, recognizing the problems most frequently detected, involving bodies of local courts and local government.

These criteria have contributed to preparing pilot projects to counter emerging situations and/or systems for goods with suggestions and directions for the conservation and management of the park.

Another interesting perspective to disseminate this heritage and involve the public would be to define the mode of networking these sites with the goal of defining itineraries/routes of high value not only from a cultural and artistic perspective, but also with regard to architecture and landscape, and therefore considerable resources to the development of a sustainable tourism in the region, raising the awareness on the varied peculiarities of the territory. 
These paths may connect to those routes of medium-long distance already existing or still to be defined, not only within the urban structure, but also in the whole region.

\section{References}

Bagnoli R (1971) Le strade di Milano: storia della città attraverso la sua toponomastica: attualità e monumenti [The streets of Milan: the city's history through its place names: current events and monuments]. Milan: Effeti.

Bianconi C (1787) Nuova guida di Milano [New Milan guide]. Milan: Sirtori.

Cali C, Capurro R (2015) Leonardo e l'acqua tra scienza e pratica a Milano. Catalogo della mostra (Milano, 23 maggio-6 settembre 2015) [Leonardo and water: between science and practice in Milan. Exhibition catalog (Milan, May 23 September 6, 2015)]. Silvana, Milan.

Cattaneo C (1844) Manifesto. Prospetto d'una raccolta di notizie naturali e civili sulla Lombardia, proposta da alcuni studiosi, per l'occasione del Congresso Scientifico di Milano [Poster. Prospect of a collection of natural and civil news on Lombardy, proposed by some academics, on the occasion of the Milan Scientific Congress]. Il Politecnico 7(38).

Council of Europe (COE) (2000) European Landscape Convention (2000). Retrieved from bit.ly/1Qvaa2o. [Accessed October 20, 2000].

Cranz G, Boland M, Chiesura A (2004) The role of urban parks for the sustainable city. Landscape and Urban Planning 68(10): 129-138.

Cranz G, Boland M (2004) Defining the sustainable park: A fifth model for urban parks. Landscape Journal 23(2): 102-120.

Cassi Ramelli A (1971) Il centro di Milano: dal Duomo alla cerchia dei Navigli. Documenti, note e divagazioni [Milan City Center: from the Dome to the ring of canals. Documents, notes and digressions ]. Milan: Meschina.

Cattaneo C (1972) Milano e l'Europa. Scritti 1839-1846 [Milan and Europe. Writings 1839-1846]. Turin: Einaudi.

Cima O (1925) Fra il verde dei giardini milanesi [Among the green gardens in Milan]. Milan: Arti Grafiche Bertarelli.

Cottini P (1994) Giardini di Lombardia [Gardens in Lombardy]. Varese: Lativa.

De Carlo V (1998) Le strade di Milano: una guida alfabetica alla storia, ai segreti, all'arte, al folclore: la vita millenaria della città rivisitata nella fitta rete delle vie e delle piazze tra curiosità, leggende, monumenti e avvenimenti memorabili [The streets of Milan: an alphabetical guide to the history, secrets, art, folklore: the thousand-year life of the city revisited in the dense network of streets and squares between curiosity, legends, monuments and memorable events]. Roma: Newton \& Compton.

Gerla R (1956) Il giardino della Guastalla [Guastalla Garden]. Milan: La martinella di Milano.

Gold S (1972) Nonuse of neighborhood parks. Journal of the American Planning Association 38(6): 369-378.

Harnik P (2010) Urban green: Innovative parks for resurgent cities. Washington DC: Island Press.

Ibes DC (2015) A multi-dimensional classification and equity analysis of an urban park system: A novel methodology and case study application. Landscape and Urban Planning 137: 122-137. 
International Council on Monuments and Sites, ICOMOS (2014) The Florence Declaration on Heritage and Landscape as Human Values (2014), Declaration of the principles and recommendations on the value of cultural heritage and landscapes for promoting peaceful and democratic societies. Retrieved from bit.ly/1cYm9IT. [Accessed November 14, 2014].

Jacobs J (1961) The death and life of great American cities. New York: Random House.

Kaźmierczak A (2013) The contribution of local parks to neighbourhood social ties. Landscape and Urban Planning 1099(1): 31-44.

Lindsey G (2003) Sustainability and urban greenways: Indicators in Indianapolis. Journal of the American Planning Association 69(2): 165-180.

Maas J, Verheij R, Groenewegen P, deVries S, Spreeuwenberg P (2006) Green space, urbanity, and health: How strong is the relation?. Journal of Epidemiology and Community Health 60(7): 587-592.

Marinoni CM (2001) Giardini a Milano [Gardens in Milan]. Milan: Mondadori.

Meijering JV, Hilde T, Van den Brink A, Morris F, Bruns D (2015) Exploring research priorities in landscape architecture: An international Delphi study. Landscape and Urban Planning 137: 85-94.

Mezzanotte P, Bascapè GC (1968) Milano nell'arte e nella storia [Milan art and history]. Milan: Bestetti, Pero.

Morigia P (1603) Historia della meravigliosa conversione, vita esemplare, e beato fine, dell'Ill. Sig. Lodovica Torella, contessa di Guastalla [History of the wonderful conversion, exemplary life, and blissful end, of the Illustrious Lady Lodovica Torella, Countess of Guastalla]. Milan: Ferioli Graziadio.

Rosignoli CG (1686) Vita e virtù della contessa di Guastalla Lodovica Torella [Life and virtues of the Countess of Guastalla Lodovica Torella]. Milan: Marelli.

Saurí D, Parés M, Domene D (2009) Changing conceptions of sustainability in Barcelona's public parks. Geographical Review 99(1): 23-36.

Various Authors (1881) Raccolta di notizie e documenti sulla fondazione, sul patrimonio e sviluppo del Regio Collegio della Guastalla in Milano [Collection of information and documents about the foundation, wealth and development of the Royal College of Guastalla in Milan]. Milan: Manini.

Waldheim C (2006) Landscape Urbanism Reader. NewYork: Princeton Architectural Press.

Zagni A (1987) La contessa di Guastalla [The Countess of Guastalla]. Reggio Emilia: Edizioni del Corno d'Oro, Reggiolo. 